\title{
Pemanfaatan Posdaya Masjid Baitussalam sebagai Pusat Pengolahan Sari Buah Markisa di Dusun Robyong, Desa Wonomulyo, Kabupaten Malang
}

\section{(The Utilization of the Posdaya Baitussalam Mosque as the Center of Passion Fruit Processing in Robyong Sub-village of Wonomulyo Village, Malang District)}

\author{
Ari Kusumastuti, Heni Widayani*, Angga Dwi Mulyanto, Hisyam Fahmi \\ Jurusan Matematika, Fakultas Sains dan Teknologi, Universitas Islam Negeri Maulana Malik Ibrahim Malang \\ Jalan Gajayana 50, Malang 65145. \\ "Penulis Korespondensi: heniwidayani@gmail.com \\ Diterima April 2018/Disetujui Januari 2019
}

\begin{abstract}
ABSTRAK
Pembentukan pos pemberdayaan keluarga (Posdaya) di Dusun Robyong, Poncokusumo, Kabupaten Malang bertujuan sebagai sarana meningkatkan pendapatan tambahan keluarga melalui pengolahan potensi alam yang ada dengan penerapan teknologi. Posdaya yang dibentuk berbasis masjid sehingga dapat memfungsikan masjid sebagai pusat sosio-ekonomi masyarakat, selain sebagai pusat keagamaan. Pada pengabdian masyarakat ini, Masjid Baitussalam menjadi proyek percontohan dalam pemberdayaan masyarakat berbasis masjid. Pelaksanaan kegiatan diawali dengan pendataan keluarga, sosialisasi, dan perumusan program kerja Posdaya sesuai potensi setempat. Setelah dilakukan diskusi dengan warga setempat, kegiatan pengolahan minuman kemasan sari buah markisa (Passiflora edulis) menjadi program kerja utama Posdaya, mengingat potensi buah markisa yang belum termanfaatkan secara optimal selama ini. Peserta program adalah warga sekitar Masjid Baitussalam, terutama ibu rumah tangga. Hasil pengamatan menunjukkan bahwa peserta berperan aktif pada program kerja Posdaya, serta didukung oleh pengurus Posdaya dan tokoh masyarakat. Produk yang dihasilkan pun direspons positif oleh pasar. Produk berhasil dipasarkan hingga ke luar Jawa sebagai buah tangan dari Desa Wonomulyo. Kegiatan wirausaha Posdaya ini dalam jangka panjang, diharapkan mampu berkembang menjadi kelompok usaha mikro dari Dusun Robyong dengan diversifikasi produk, penerapan strategi pemasaran, dan manajemen produksi yang semakin baik.
\end{abstract}

Kata kunci: markisa, masjid, Posdaya

\begin{abstract}
The formation of the family empowerment post (Posdaya) at Robyong Sub-village of Poncokusumo is intended to increase family income through the application of technology to utilize existing natural potential endowment. The mosque-based family empowerment post could functionalize mosque as a social-economic community center as well as a religious activity center. The community empowerment program at BaitussalamMosque Posdaya has become a pilot project in the mosque-based society empowerment. The implementation of the program consisted of family data collection, socialization, and determination of the Posdaya main program according to local potential. Discussion with locals has concluded that the need for training about passion fruit (Passiflora edulis) processing as a main program of Posdaya, since passion fruit has become potential and not yet being utilized optimally. Participants are locals around Baitussalam Mosque, especially housewives. Direct observation shows that locals actively participate in the Posdaya program and supported also by Posdaya organizer and community leaders. The resulting product was responded positively by the market. The product was already marketed out of Java as a souvenir from the Robyong sub-village of Poncokusumo. This program is expected to become a micro-group enterprise from Robyong sub-village with product diversification, good marketing strategy, and good production management in the future.
\end{abstract}

Keywords: mosque, passion fruit, Posdaya

\section{PENDAHULUAN}

Pengabdian masyarakat merupakan salah satu peran akademisi untuk dapat mengimple- mentasikan keilmuan dan kemampuan yang dimiliki untuk mencari solusi yang tepat dan efektif atas permasalahan masyarakat. LP2M UIN Malang melakukan pengabdian masyarakat 
secara berkarakter, yakni dengan memberdayakan warga muslim menjadi lebih berdikari dengan semangat persaudaraan sesama muslim.

Pemberdayaan dimaknai sebagai suatu proses pemberian kemampuan dari pihak yang mempunyai kemampuan kepada pihak yang kurang atau belum berdaya (Sulistiyani 2004). Di sini, peran akademisi adalah sebagai fasilitator ataupun mediator dalam penyaluran kemampuan tersebut. LP2M UIN Malang melalui tim Kuliah Kerja Mahasiswa (KKM) 180 melakukan pemberdayaan sekunder, di mana menurut Prijono dan Pranarka (1996), pemberdayaan sekunder adalah melihat pemberdayaan sebagai proses menstimulasi, mendorong, atau memotivasi individu agar memiliki kemampuan atau keberdayaan untuk menentukan apa yang menjadi pilihannya. Hal ini bertujuan agar akademisi benar-benar menjadi pemikir akan solusi faktual di masyarakat bukan memaksa mengimplementasikan teori yang dipelajari.

Menurut Sulistiyani (2004) pemberdayaan tidak bersifat selamanya, melainkan sampai target masyarakat mampu untuk mandiri, dan kemudian dilepas untuk mandiri, meski dari jauh dijaga agar tidak kembali menjauh. Muljono (2011) menyatakan salah satu pemberdayaan masyarakat dapat dilakukan melalui Posdaya. Posdaya merupakan wadah antar-keluarga yang kondisi sosial-ekonomi dan budayanya bervariasi yang bertujuan untuk pemberdayaan keluarga untuk memperkuat potensi yang dimiliki oleh setiap keluarga. Posdaya dapat dibentuk melalui berbagai lembaga yang sudah ada di masyarakat misalnya berbasis masjid, pesantren, atau komunitas yang ada di masyarakat (LP2M UIN Malang 2016).

LP2M UIN Malang menerjemahkan pengabdian masyarakat melalui Posdaya berbasis masjid. Berbeda dengan pemberdayaan posdaya yang telah dilakukan oleh Anwas (2010); Anwas (2012); Saleh et al. (2014); Bachtiar (2016); Triyono (2017) yang berbasis masyarakat. Posdaya berbasis masjid menurut Suyono (2016) dinilai lebih efektif karena tokoh-tokoh agama dapat menghadirkan pengaruh positif yang seringkali lebih besar dibanding tokoh masyarakat yang lain.

Masjid merupakan tempat yang sangat strategis untuk menjadi pusat kegiatan masyarakat. Peran masjid seharusnya tidak hanya terbatas dalam peribadatan, namun juga berperan penting dalam kegiatan sosial-ekonomi masyarakat. Masjid diharapkan mampu memberikan kemanfaatan pada semua lapisan masyarakat, terutama warga di sekitar masjid. Karakter masyarakat sekitar masjid yang mayoritas muslim religius dengan tingkat kesejahteraan yang rendah harus mendorong masjid sebagai pusat pemberdayaan (empowering) dan percontohan dalam menggerakkan kegiatan dan mengubah kesejahteraan masyarakat sekitar menjadi lebih baik.

Pada program pengabdian Posdaya berbasis masjid ini, dipilih Masjid Baitussalam yang terletak di Dusun Robyong, Poncokusumo, Kabupaten Malang sebagai percontohan. Hal ini disebabkan karena Masjid Baitussalam adalah masjid utama di Dusun Robyong dengan sarana dan prasarana yang lengkap dan baik. Kegiatan keagamaan dalam bentuk pengajian sudah berjalan dengan maksimal didukung oleh pastisipasi aktif dari masyarakat. Hasil observasi Kusumastuti (2016), menyatakan pengelolaan manajeman keuangan masjid berjalan dengan baik dan transparan di mana terdapat beberapa anak asuh yang dibiayai pendidikannya sampai tingkat perguruan tinggi. Terdapat beberapa organisasi pendukung aspek keagamaan di dalam kepengurusan masjid antara lain takmir, remas, dan keputrian. Semua organisasi tersebut mendapat dukungan dan pastisipasi dari warga sekitar, sekalipun keadaan ekonomi warga masih sebatas buruh tani ataupun buruh ternak.

Penduduk sekitar Masjid Baitussalam mayoritas bermata pencaharian sebagai petani sayur dan palawija. Profil tanah yang landai, subur, dan sarana irigasi yang memadai mendukung proses pertanian di Dusun Robyong. Pertanian dan pengolahan hasil pertanian masih dilakukan secara tradisional sehingga kurang menambah nilai jual dari produk. Tingkat pendidikan yang rendah $(0,86 \%$ warga yang pernah duduk di bangku kuliah) menyebabkan petani lebih cenderung untuk menjual hasil pertanian kepada tengkulak karena tidak bisa menentukan harga (Anwar et al. 2016). Hal ini menyebabkan kesejahteraan ekonomi warga belum cukup baik. Jumlah ibu rumah tangga yang menganggur tergolong cukup banyak. Sekalipun sudah ada program PKK untuk perberdayaan ibu rumah tangga dalam kewirausahaan, nampaknya belum memberikan dampak signifikan pada perubahan ekonomi keluarga. Potensi tanah subur dengan pemanfaatan lahan sekitar rumah dengan tanaman pisang, jambu, dan markisa merupakan potensi daerah Robyong yang dapat dikembangkan menjadi produk olahan layak jual.

Penduduk Dusun Robyong memiliki aspek kesejahteraan yang kurang, namun karakter 
religius mereka kuat. Hal ini terbukti dari tingginya partisipasi masyarakat untuk mengikuti kegiatan keagamaan yang diumumkan oleh takmir masjid. Seringnya kegiataan rutin warga seperti khataman, diba'an, yasinan, istighosa, manakib, dan tahlil semakin memperkuat karakter religius yang dimiliki oleh warga Dusun Robyong (Anwar et al. 2016). Oleh karena itu, pengabdian masyarakat melakukan pemberdayaan keluarga berbasis masjid sehingga mudah mengajak masyarakat untuk bersamasama mencari solusi atas masalah peningkatan kesejahteraan ekonomi yang dihadapi keluarga di Dusun Robyong. Posdaya Masjid Baitussalam Dusun Robyong, Poncokusumo, Kabupaten Malang bertujuan sebagai sarana meningkatkan pendapatan tambahan keluarga melalui pengolahan potensi alam yang ada dengan penerapan teknologi. Pada akhir program pengabdian ini diharapkan bahwa masyarakat dapat melakukan usaha pengolahan minuman kemasan sari buah, khususnya markisa dengan diorganisir oleh Posdaya Masjid Baitussalam dan diarahkan oleh TIM KKM 180 UIN Malang.

\section{METODE PELAKSANAAN KEGIATAN}

\section{Lokasi dan Partisipan}

Kegiatan ini dilakukan di Dusun Robyong, Desa Wonomulyo, Kecamatan Poncokusumo, Kabupaten Malang, Jawa Timur. Posdaya berpusat di Masjid Baitussalam. Pelaksanaan kegiatan dilakukan pada tanggal 20 Juli-20 Agustus 2016. Kegiatan pelatihan ini diikuti oleh 28 orang yang merupakan perwakilan Remas Masjid Baitussalam, karang taruna, PKK, Kewanitaan dan Keputrian Dusun Robyong, dan Pengurus Posdaya, serta perwakilan warga Robyong.

\section{Bahan dan Alat}

Bahan utama yang diperlukan dalam kegiatan pengabdian ini adalah buah markisa. Sedangkan, bahan penunjang untuk pembuatan minuman kemasan sari buah markisa, antara lain gula pasir, air mineral (air bersih), es batu, dan gula pasir. Peralatan yang dibutuhkan adalah pisau, blender, kompor, panci, pengaduk, timbangan, saringan, kemasan plastik, kardus, dan cup sealer.

\section{Prosedur Kegiatan}

Tahapan pelaksanaan kegiatan sebagai berikut:

- Tahap persiapan, yakni sosialisasi tujuan, target, dan luaran program pengabdian ke pemerintah setempat (perangkat dusun, RW, RT, dan Takmir Masjid Baitussalam) sehingga kegiatan ini mendapat dukungan sosial dan dapat terlaksana dengan baik dan lancar.

- Tahap pelaksanaan: a) Pendataan dan penyusunan peta keluarga; b) Pembentukan pengurus Posdaya Masjid Baitussalam; c) Identifikasi program kerja utama Posdaya berdasarkan masalah dan potensi dengan masyarakat setempat; d) Pelatihan pengolahan minuman kemasan sari buah markisa; dan e) Pendampingan teknis proses produksi, pengemasan, perizinan, dan pemasaran produk.

- Tahap evaluasi meliputi kegiatan pemantauan terhadap penyerapan produk oleh pasar, evaluasi proses produksi dan produk, evaluasi pemasaran, dan evaluasi dampak program. Hasil dari tahap ini merupakan maintenance produk untuk produksi, distribusi, dan pemasaran.

\section{HASIL DAN PEMBAHASAN}

\section{Tahap Persiapan}

Sosialisasi program pengabdian oleh Tim KKM 180 UIN Malang dilaksanakan pada tanggal 20 Juli 2016 pukul 19.00 WIB di Masjid Baitussalam. Kegiatan ini dihadiri oleh kepala dusun, perangkat dusun, RT/RW, PKK, takmir masjid, keputrian, dan tokoh masyarakat. Proses sosialisasi dan diskusi menghasilkan kesimpulan awal bahwa Masjid Baitussalam sudah memiliki Posdaya, namun sudah lama tidak aktif. Oleh karena itu, dengan arahan dari TIM KKM 180 UIN Malang disepakati untuk membentuk susunan pengurus Posdaya yang baru dan menfokuskan program kerja Posdaya dalam bidang kewirausahaan sehingga berdampak pada meningkatnya perekonomian masyarakat setempat.

\section{Tahap Pelaksanaan}

Pada tanggal 21-24 Juli 2016 dilakukan pendataan keluarga secara langsung oleh Tim KKM 180 UIN Malang. Sasaran pendataan ini adalah 89 keluarga di sekitar Masjid Baitussalam. Pendataan keluarga menggunakan form register pendataan keluarga LP2M yang memuat indikator-indikator keluarga sejahtera, sehingga keluarga dapat terklasifikasi tingkat kesejahteraannya. Taraf kesejahteraan keluarga Posdaya Masjid Baitussalam sebagaimana ditunjukkan pada Gambar 1 diperoleh dari hasil pendataan 
ini. Keluarga sejahtera II mendominasi lingkungan sekitar Masjid Baitussalam (50,56\% atau 45 keluarga), namun masih ada sebanyak 16 keluarga prasejahtera dan 16 keluarga sejahtera I dikarenakan masalah kesehatan, perumahan, dan pangan. Masalah kesehatan yang terjadi cukup bertolak belakang dengan kondisi Dusun Robyong yang kaya dengan potensi alam baik untuk tanaman pangan maupun obat-obatan. Hal ini dapat menjadi fokus oleh pemerintah setempat untuk dapat ditangani.

Tim KKM 180 UIN Malang membuat peta keluarga Posdaya Masjid Baitussalam (Gambar 2) untuk menjelaskan keadaan tingkat kesejahteraan warga dari hasil pendataan. Hal ini bertujuan agar mudah untuk mengidentifikasi lokasi rumah keluarga, terutama keluarga prasejahtera sehingga dapat dipikirkan bersama cara untuk meningkatkan kesejahteraan dari keluarga tersebut dengan perangkat dusun dan warga sekitar.

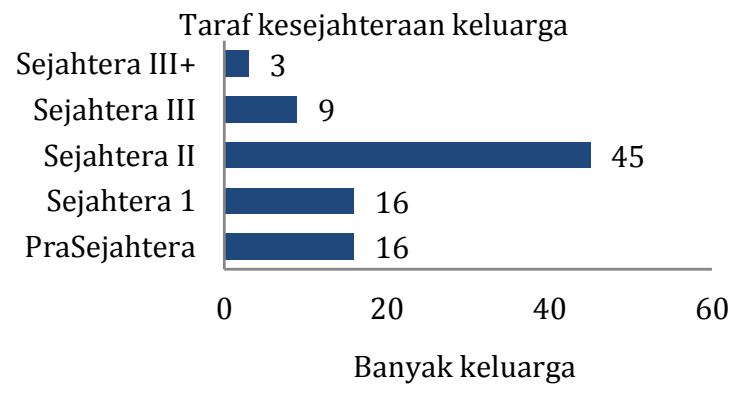

Gambar 1Taraf kesejahteraan keluarga Posdaya Masjid Baitussalam.
Selain membuat peta keluarga Posdaya Masjid Baitussalam, tim KKM UIN Malang dengan masyarakat sekitar menginisiasi pembentukan susunan baru pengurus Posdaya. Perombakan kepengurusan ini bertujuan agar Posdaya yang baru dapat lebih aktif di bidang kewirausahaan sebagai langkah untuk meningkatkan perekonomian masyarakat sekitar. Selain bidang kewirausahaan, posdaya juga memiliki bidang pendidikan, keagamaan, dan kesehatan sebagai langkah peningkatan kesejahteraan selain aspek ekonomi. Pada bagan kepengurusan Posdaya (Gambar 3), LP2M UIN Malang memiliki tugas sebagai tim monitoring kinerja Posdaya.

Setelah dilakukan diskusi dengan tokoh dan warga setempat terkait masalah dan potensi alam di Dusun Robyong, diperoleh kesepakatan untuk mengutamakan program kerja Posdaya Masjid Baitussalam dalam aspek kewirausahaan, yakni mengolah buah markisa menjadi minuman kemasan siap minum. Hal ini dimotivasi oleh tanaman markisa yang hampir menjadi tanaman penghias di setiap rumah warga, tetapi buah markisa jarang sekali dimanfaatkan. Pada waktuwaktu tertentu seperti Hari Raya Idul Fitri, markisa secara tradisional disajikan menjadi minuman untuk tamu. Selain waktu tersebut, buah markisa lebih banyak dibiarkan atau malah dibuang. Potensi markisa ini bisa menjadi peluang usaha mikro keluarga di Dusun Robyong. Selain itu, teknik produksi minuman sari markisa ini dapat diadaptasi untuk sari buah lain, seperti apel, anggur, delima, dan jeruk. Sehingga

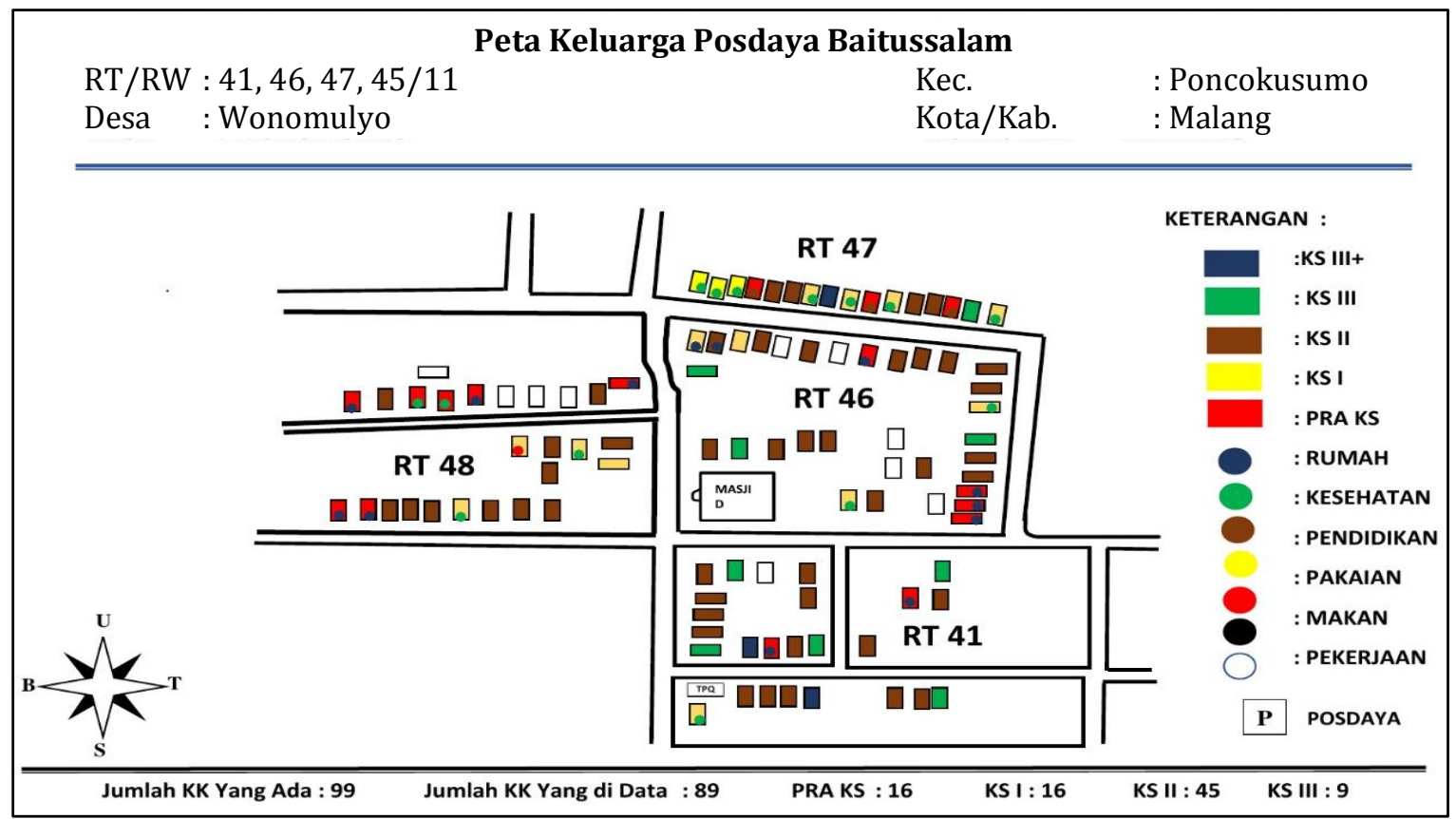

Gambar 2 Peta kesejahteraan keluarga Posdaya Masjid Baitussalam. 
Susunan Pengurus Posdaya Baitussalam

Desa: Wonomulyo

Kec.: Poncokusumo

Kota/Kab: Malang

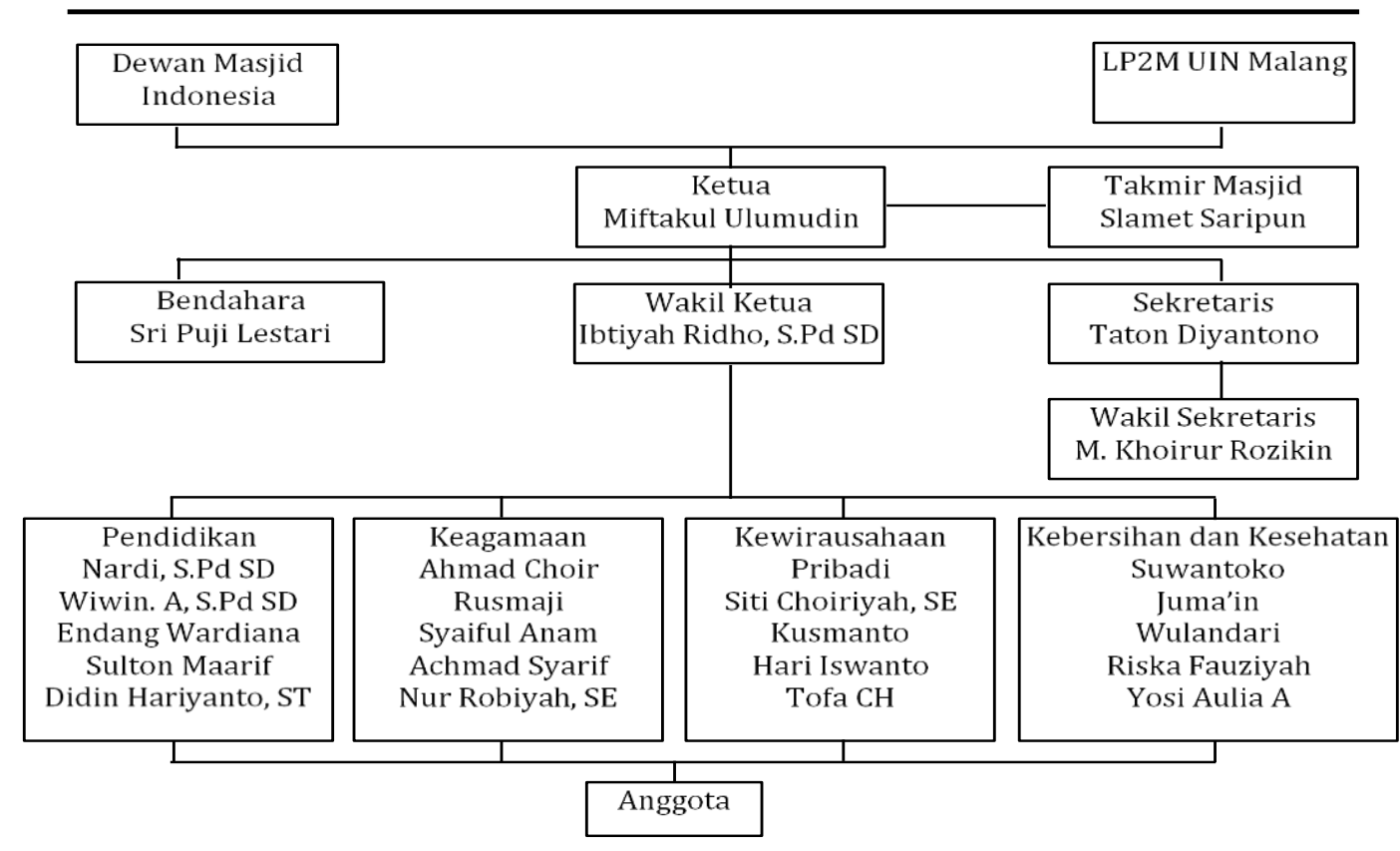

Gambar 3 Bagan kepengurusan Posdaya Masjid Baitussalam.

diversifikasi produk sari buah dapat dilakukan di masa yang akan datang.

Pelatihan pembuatan minuman sari buah markisa dilaksanakan pada 13 Agustus 2016 pukul 15.00-17.00 WIB (Gambar 4). Kegiatan ini diikuti oleh Remaja Masjid, Karang Taruna, PKK, Keputrian, Pengurus Posdaya, serta warga sekitar. Pembicara pelatihan merupakan perwakilan dari Balai Latihan Kerja yang merupakan Tim Binaan Disnaker Provinsi Jawa Timur. Materi pelatihan mencakup teknik produksi, pengemasan, dan pengajuan PIRT pada Departemen Kesehatan. Strategi pemasaran minuman sari buah menjadi materi penutup, sehingga peserta mendapatkan gambaran tentang peluang usaha minuman sari buah.

Hasil implementasi dari pelatihan dikelola oleh pengurus Posdaya Masjid Baitussalam sehingga proses produksi, pengemasan, dan pemasaran produk dapat dilaksanakan dengan sistematis. Pengurus Posdaya juga bertugas untuk menggalakkan pemanfaatan lahan kosong, terutama pekarangan rumah keluarga sebagai tempat penanaman markisa. Tidak menutup pula kemungkinan untuk menggunakan tanaman markisa sebagai tanaman selingan di lahan pertanian, sehingga lahan kosong yang ada akan menjadi sumber tambahan pendapatan untuk setiap keluarga.

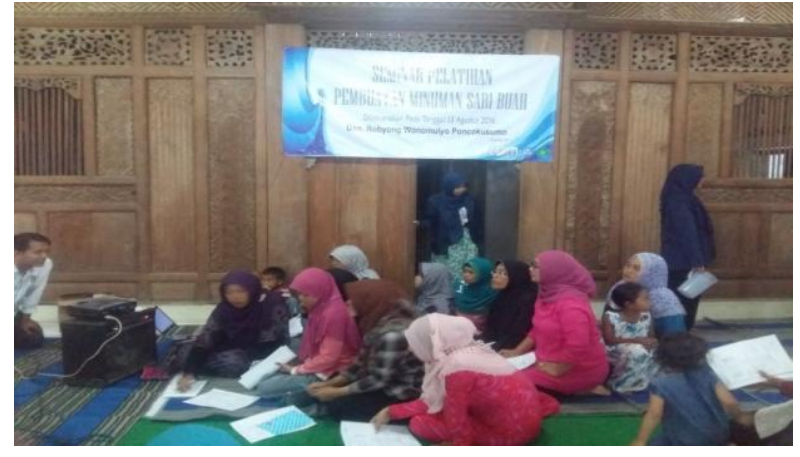

Gambar 4 Pelatihan pembuatan sari buah markisa.

\section{Tahap Evaluasi}

Pada tahap ini dilakukan proses monitoring pengemasan dan pemasaran produk minuman sari buah markisa. Gambar 5 merupakan produk minuman kemasan sari buah markisa yang siap dipasarkan. Produk sudah memiliki PIRT dengan kemasan yang menarik. Monitoring proses produksi dan pengemasan dilakukan oleh TIM KKM 180 UIN Malang agar kualitas produk terjamin dan pengarahan teknis lebih lanjut untuk mengembangkan usaha sari buah ini. Dari hasil pemantauan di lapangan, warga sekitar memiliki antusias tinggi untuk berperan dalam program kewirausahaan Posdaya, baik dalam proses bahan baku, produksi, pengemasan, maupun pemasaran. Pengurus Posdaya juga berkomitmen tinggi dalam mengorganisir antusiasme warga dan dalam keberlanjutan program kerja yang telah disepakati bersama. 


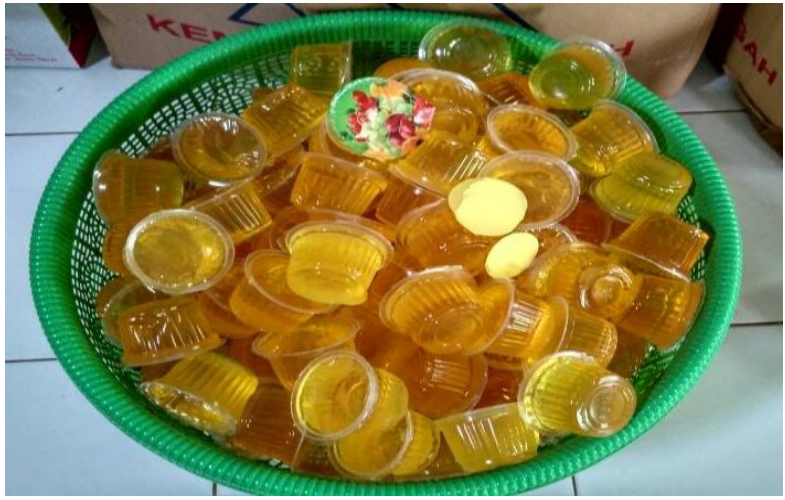

Gambar 5 Produk minuman kemasan sari buah markisa siap dipasarkan.

\section{SIMPULAN}

Posdaya berbasis masjid di Dusun Robyong, Desa Wonomulyo merupakan bentuk pengabdian masyarakat yang berfokus pada pemberdayaan Masjid Baitussalam sebagai proyek percontohan pemberdayaan keluarga. Tujuan utamanya adalah memfungsikan masjid bukan hanya sebagai pusat kegiatan keagaamaan, namun juga kegiatan sosial-ekonomi masyarakat. Keberlanjutan program Posdaya yang sudah ada diharapkan dapat terealisasi dengan komunikasi yang berkesinambungan antara pihak UIN Maulana Malik Ibrahim Malang dengan masyarakat Dusun Robyong. Dengan demikian, peran akademisi sebagai penyelesaian masalah yang ada di masyarakat dengan keilmuan dan teknologi tepat guna benar-benar dapat terwujud. Keberlanjutan program Posdaya Masjid Baitussalam pada pengolahan minuman sari buah markisa ini harus difokuskan pada keberlanjutan pemanfaatan lahan pekarangan sekitar rumah untuk penanaman buah markisa sebagai bahan baku produk minuman sari buah markisa. Program ini akan sukses manakala ditindaklanjuti oleh pihak-pihak terkait utamanya sinergi dan kerja sama antara LP2M UIN Maulana Malik Ibrahim serta pemangku kebijakan di wilayah Poncokusumo.

\section{UCAPAN TERIMA KASIH}

Terima kasih kepada Lembaga Penelitian dan Pengabdian Masyarakat (LP2M) Universitas Islam Negeri Maulana Malik Ibrahim Malang, TIM KKM 180 UIN Malang, Ibu Aminah, Bapak Budi, dan Ibu Ngatinah sebagai narasumber pelatihan, serta kepala dusun, perangkat dusun, perwakilan RT/RW, PKK, takmir, kewanitaan, keputrian, jamaah masjid, dan tokoh-tokoh agama di sekitar Masjid Baitussalam, Dusun Robyong, Desa Wonomulyo yang telah mendukung serangkaian kegiatan pengabdian masyarakat ini.

\section{DAFTAR PUSTAKA}

Anwar MK, Sutisna FI, Fachri R, Ramadhan F. 2016. Laporan Praktikum Pemberdayaan Masyarakat di Desa Wonomulyo, Kecamatan Poncokusumo, Kabupaten Malang. Laboratorium Agribisnis Fakultas Pertanian Peternakan. Malang (ID): Universitas Muhammadiyah.

Anwas OM. 2010. Model Posdaya Dalam Penuntasan Wajib Belajar Pendidikan Dasar 9 Tahun. Jurnal Pendidikan dan Kebudayaan. 16(2): 206-214. https://doi.org/10.24832/ jpnk.v16i2.447

Anwas OM. 2012. Model PAUD Posdaya sebagai Alternatif Pelaksanaan Pendidikan Anak Usia Dini Berbasis Masyarakat. Jurnal Pendidikan dan Kebudayaan. 18(3): 319-327. https://doi.org/10.24832/jpnk.v18i3.91

Bachtiar Y. 2016. Posdaya Bina Sejahtera Kota Bogor sebagai Model Pemberdayaan Kemandirian Masyarakat Akar Rumput. Agrokreatif Jurnal Ilmiah Pengabdian kepada Masyarakat. 2(1): 31-38. https://doi.org /10.29244/agrokreatif.2.1.31-38

Kusumastuti A. 2016. Laporan Kuliah Kerja Mahasiswa Tematik Posdaya Berbasis Masjid di Masjid Baitussalam Desa Wonomulyo Kecamatan Poncokusumo Kabupaten Malang. Malang (ID): LP2M Universitas Islam Negeri Maulana Malik Ibrahim Malang.

LP2M UIN Maulana Malik Ibrahim Malang. 2016. Pedoman Kuliah Kerja Nyata (KKN) Tematik Posdaya Berbasis Masjid Universitas Islam Negeri (UIN) Maulana Malik Ibrahim. Malang (ID): UIN Maulana Malik Ibrahim.

Muljono P. 2011. The Model of Family Empowerment Program for Community Empowerment in West Java, Indonesia. Journal of Agricultural Extension and Rural Development. 3(11): 193-201.

Prijono OS, Pranarka AMW. 1996. Pemberdayaan: Konsep, Kebijakan, dan Implementasi. Jakarta (ID): Centre for Strategic and International Studies (CSIS). 
Sulistiyani AT. 2004. Kemitraan dan model-model Pemberdayaan. Yogyakarta (ID): Gava Media.

Suyono H. 2016. Posdaya Berbasis Masjid Dinilai Lebih Efektif. dalam Sriwijaya Post, Tribunnews Palembang, Rabu, 27 Januari 2016. [Internet]. [diunduh 2018 Maret 31]. Tersedia pada: http://palembangtribunnews. com/2016/01/27/posdaya-berbasis-masjiddinilai-lebih-efektif.

Saleh A, Rokhani, Bahtiar R. 2014. Support External Relations and Entrepreneurship
Through Social Capital Model against Posdaya in Bogor, Bogor and Cianjur Districts. Kesejahteraan Sosial (Journal of Social Welfare). 1(1): 25-38.

Triyono A. (2017). Pemberdayaan Masyarakat Melalui Community Development Program Posdaya (Pos Pemberdayaan Keluarga) Pt. Holcim Indonesia Tbk Pabrik Cilacap. Komuniti: Jurnal Komunikasi dan Teknologi Informasi. 6(2): 111-121. 